19 Revue d'histoire du XIXe siècle

Société d'histoire de la révolution de 1848 et des

révolutions du XIXe siècle

$32 \mid 2006$

Varia

\title{
Les photographies des ruines de Paris en 1871 ou les faux-semblants de l'image
}

Photographs of the ruins of Paris in 1871, or the pretences of pictures

\section{Éric Fournier}

\section{OpenEdition}

\section{Journals}

Édition électronique

URL : http://journals.openedition.org/rh19/1101

DOl : $10.4000 /$ rh 19.1101

ISSN : $1777-5329$

\section{Éditeur}

La Société de 1848

\section{Édition imprimée}

Date de publication : 1 juin 2006

Pagination : 137-151

ISSN : 1265-1354

Référence électronique

Éric Fournier, «Les photographies des ruines de Paris en 1871 ou les faux-semblants de l'image », Revue d'histoire du XIXe siècle [En ligne], 32 | 2006, mis en ligne le 30 octobre 2008, consulté le 19 avril 2019. URL : http://journals.openedition.org/rh19/1101 ; DOI : 10.4000/rh19.1101 


\section{ÉRIC FOURNIER}

\section{Les photographies des ruines de Paris en 1871 ou les faux-semblants de l'image}

Au printemps 1871, la bataille de Paris et la «semaine sanglante» produisent un paysage urbain unanimement considéré comme dantesque par les témoins du drame. La capitale et sa proche banlieue deviennent un champ de bataille au milieu duquel émergent des destructions si troublantes que de nombreux contemporains n'hésitent pas à les considérer comme des ruines édifiantes. Il est important de savoir à quoi ressemblaient effectivement les destructions parisiennes de 1871 afin de déterminer l'influence de la poétique des ruines sur tous ceux qui s'essayent alors à décrire ces paysages éphémères. Car l'on voit alors volontiers dans les ruines du ministère des Finances «un coin de Pompéi ou d'Herculanum, une page lacérée des vieilles civilisations tout à coup transportée dans la capitale des civilisations nouvelles", comme l'écrit Frédéric Fort ${ }^{1}$.Une rhétorique ruiniste se déploie, investissant des supports qui ne ressemblent guère à des ruines antiques ou médiévales, voire des monuments à peine dégradés. La production littéraire sur ce sujet est donc à considérer avec précaution ${ }^{2}$.

Nous sommes donc confrontés à un problème simple : quel était l'aspect de ces ruines? C'est ici qu'apparaît l'image photographique. Le monde de la photographie espère obtenir à cette époque, par son traitement de "l'année terrible», une reconnaissance accrue. Les photographes s'emparent des ruines de Paris et s'efforcent de faire triompher la représentation photographique de ces décombres. Les registres du dépôt légal soulignent l'investissement des ruines par les photographes : en 1871, 50\% des dépôts photographiques, soit 1800 clichés, traitent de la Commune de Paris, dont les deux tiers portent sur les ruines ${ }^{3}$. Depuis la guerre de Crimée, le public est persuadé que

1. Frédéric FORT, Paris brûlé, Paris, Librairie Lachaud, 1871, p. 89.

2. Une analyse plus poussée suggère l'hétérogénéité des discours qui traduit l'atomisation des réactions, en fonction de l'attrait pour la ruine, de l'ampleur du traumatisme ressenti, et des considérations politiques propres à chaque écrivain. Pour de plus amples développements, voir Eric FOURNIER, Paris en ruines (1851-1882) : entre flanerie et apocalypse. Regards, acteurs, pratiques, thèse d'histoire sous la direction de Dominique Kalifa, Université Paris I-Panthéon Sorbonne, 2005, pp. 340-342.

3. Quentin BAJAC, «Les artilleurs du collodion», dans Quentin BAJAC [dir.], La Commune photographiée, Paris, Éditions de la Réunion des Musées Nationaux, 2000, p. 6. 
cette technique émergente est plus apte que la peinture historique à restituer la réalité des champs de bataille ${ }^{4}$. La photographie apparaît alors comme un œil-témoin mécanique et dépassionné offrant un rapport immédiat à l'événement, dépouillé de tout artifice artistique ${ }^{5}$. Ce qu'elle n'est pas. Comme tout document, la photographie doit être décryptée. Telle est l'ambition du dossier que nous présentons ici. Les photographies des destructions de 1871, peuvent être interrogées selon trois axes. Quelles sont les différentes stratégies photographiques? Quel est le rapport sensible des photographes à l'espace parisien? Enfin, qu'est ce que la photographie, techniquement, ne peut pas montrer par rapport à d'autres images, dessinées ou peintes?

\section{LES STRATÉGIES PHOTOGRAPHIQUES}

Les objectifs que se fixent les photographes déterminent des pratiques précises, que ce soit dans le choix des sujets ou dans les compositions. Ceux-ci espèrent obtenir une reconnaissance en tant que spécialistes des ruines et acteurs du retour à l'ordre.

L'importance de la production photographique traitant des ruines de Paris témoigne en effet du lien fondateur entre publications de photographies et représentation des ruines au XIX $\mathrm{X}^{\mathrm{e}}$ siècle. Ainsi, la première publication d'un recueil photographique, rendu techniquement possible en 1851, traitait-elle des ruines orientales: Egypte, Nubie, Palestine et Syrie, dessins photographiques recueillis dans les années 1849, 1850 et 1851, de Maxime Du Camp, édité en 1852. Parallèlement, en 1851, la commission des monuments historiques envoyait une mission héliographique fixer tant les bâtiments menacés de ruine que les ruines menacées d'écroulement. Cent vingt sites furent photographiés par cette mission, à laquelle participèrent les photographes les plus connus de l'époque, comme Baldus. Commentant cette œuvre de sauvegarde photographique, Ernest Lacan, éditorialiste du Moniteur de la photographie, résolument convaincu du lien étroit entre ruines et photographies ${ }^{6}$, fait $\mathrm{du}$ photographe la figure inverse du démolisseur : si le second détruit à jamais, le premier conserve pour l'éternité, constituant ainsi de précieuses archives de civilisation. Confrontés aux ruines éphémères de la capitale, les photographes, dans la continuité de la mission héliographique, se sentent plus que jamais investis de la fonction de les fixer sur le papier ${ }^{7}$.

Les photographes du Second Empire ont eu également tendance à se percevoir comme des auxiliaires de l'autorité et de l'armée. Accompagnant

4. Hélène PUISEUX, Les figures de la guerre, représentations et sensibilités 1839-1996, Paris, Éditions Gallimard, 1997, p. 77.

5. Idem, p. 78 et André ROUILLÉ, L'empire de la photographie (1839-1870), Paris, Éditions du Seuil, 1982, pp. 147-155.

6. Hélène PUISEUX, Les figures de la guerre..., ouv. cité, pp. 23 et 28.

7. Ernest LACAN, «Éditorial» du Moniteur de la photographie, $1^{\text {er }}$ août 1871. 
les armées en campagne, de la Crimée au Mexique, ils s'efforcent de garder une trace, non seulement des opérations militaires (ou plus précisément des champs de bataille et des uniformes), mais aussi des nations vaincues, voire des civilisations déchues. La photographie intègre alors la propagande impériale. Dès la victoire versaillaise, cette fonction est réactivée par les autorités, qui chargent le $1^{\text {er }}$ juin Ernest Lacan et ses confrères de reproduire certains bâtiments à destination des services d'architectures et de photographier les dévastations. Ceci explique le caractère presque exhaustif des clichés. Pourtant, en isolant soigneusement les ruines du bâti préservé, les photographes créent une image déformée qui tend à exagérer l'ampleur des destructions subies par la capitale. «Le plus grand trucage, la plus forte invention de la photographie de 1871 est bien le spectacle d'un Paris ruiné. Les photographes construisent la fiction d'un Paris détruit ${ }^{8}$. En d'autres termes, les photographes, loin d'être les serviteurs d'un œil-témoin dépassionné participent pleinement au discours versaillais de condamnation. Constatant l'importance des ruines dans la production photographique, Christine Lapostolle estime que «la photographie se laisse littéralement fasciner par les ruines.» ${ }^{9}$. Certes, mais les photographes essayent tout autant de fasciner l'opinion par le biais des ruines, de la convaincre ainsi du potentiel de la photographie.

\section{LE RAPPORT SENSIBLE À LA CAPITALE}

Les photographes souhaitent se distinguer des dessinateurs et des écrivains. Pourtant, leur rapport sensible aux destructions de l'agglomération parisienne differe assez peu de celui de leurs concurrents. Aussi privilégient-ils les monuments du centre historique de Paris qui, convenablement cadrés, peuvent former des ruines honorables. Ils n'hésitent pas à s'aventurer dans le dédale des débris pour dénicher le micro-paysage qui offre l'illusion de la ruine ancienne (voir documents 3, 5 et 7).

Si les ruines du centre bénéficient d'un traitement photographique pompéien, celles des quartiers annexés ou de la proche banlieue évoquent plutôt des champs de bataille (documents 8 et 9). De la même manière que les écrivains ne voient pas de ruines aux périphéries de la capitale, mais seulement les ravages de la guerre ${ }^{10}$, les photographes insistent, en de vastes panoramas, sur des fortins, des tranchées, des batteries abandonnées, des arbres déracinées et, pour les forts de Vanves et d'Issy, des terrains lunaires, défigurés par la canonnade. L'influence des photographies de la guerre de Crimée est ici certaine. Si les photographies des vestiges du centre invitent le spectateur à

8. Christine LAPOSTOLLE, «La Commune de la barricade à la ruine», La Recherche photographique, $\mathrm{n}^{\circ} 4$, juin 1989, p. 23.

9. Idem, p. 22.

10. Éric FOURNIER, Paris en ruines (1851-1882)..., thèse citée, pp. 391-409. 
adopter le regard des amateurs de ruines, celles de la périphérie proposent le regard du soldat embrassant l'ensemble d'un champ de bataille.

Cependant, s'efforçant d'être le plus exhaustif possible, les photographes mettent en évidence le potentiel ruiniste de certains décombres, tel le Grenier d'abondance du boulevard Bourdon (documents 2 et 3), délaissé par la production écrite car trop excentré, et ne disposant pas d'un passé prestigieux ou d'un potentiel symbolique susceptible de le transformer en ruine.

\section{CE QUe la Photographie ne PeUt pas MONTRER}

Les conditions techniques de l'époque brident les sujets possibles. Le temps de pose de plusieurs secondes interdit de fixer le mouvement. Ainsi le moment de la destruction, le plus souvent par l'incendie, ne peut pas être photographié, alors même qu'il a été abondamment dessiné (document 6). De surcroît, les personnages présents sur les vues photographiques sont dans des postures figées. Il est donc presque impossible de représenter le travail des pompiers ou des terrassiers, c'est-à-dire l'élision des traces, ou les foules se promenant dans les ruines dès la fin des combats. En d'autres termes, les photographes peuvent difficilement représenter les processus du retour à l'ordre, alors même qu'ils se définissent comme des auxiliaires de l'autorité (document 1).

Enfin, ces clichés restent monochromes. Or la coloration singulière des vestiges a fasciné l'ensemble des amateurs de ruines. "L'incendie a revêtu toutes les murailles d'une teinte dorée qu'aucun art ne saurait produire. Quand le soleil vient jouer là-dessus, on arrive à des effets merveilleux que les peintres achèteraient fort chers", écrit par exemple William Erskine face aux ruines de l'Hôtel de Ville ${ }^{11}$. Les photographes sont impuissants face aux lithographies de mauvaise qualité, qui sont souvent des clichés approximativement coloriés et sont largement diffusés sur les étals parisiens.

\section{Conclusion}

Alors que les photographes professionnels s'efforcent de se distinguer des écrivains, leurs pratiques des destructions parisiennes soulignent qu'ils sont également influencés par des codes d'appréciation identiques : dès qu'il s'agit des paysages du centre, poésie de Paris et poétique des ruines rentrent en résonance. Mais, une fois décryptée, cette production photographique reste, faute de mieux, le meilleur moyen de restituer le paysage sensible qui s'est

11. Georges BELL [pseudonyme de Joachim Houreau], Paris incendié, histoire de la Commune de 1871, Paris, Librairie Martinet-A. Marc, 1872, p. 138. 
offert aux Parisiens amateurs de ruines. Ce corpus permet à la manière d'une caméra subjective, dans une approche compréhensive donc, de reconstituer la découverte des ruines, les étapes du parcours, des façades aux intérieurs, de ceux qui cherchent des ruines dans ces décombres. Le supposé œil-témoin mécanique se révèle alors utile pour apprécier le regard sensible des visiteurs des ruines.

Éric Fournier est docteur en histoire de l'Université de Paris I. 


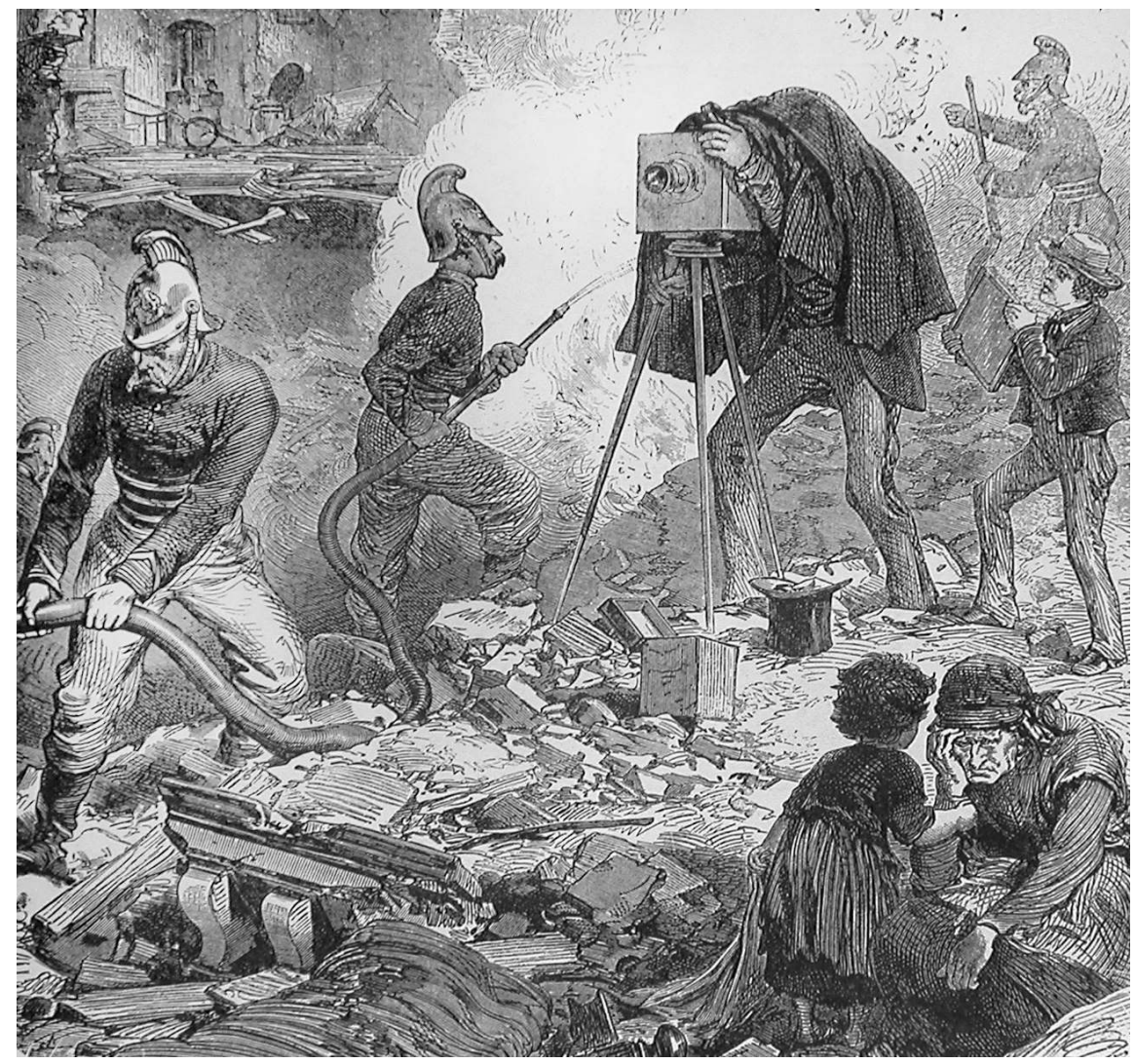

Document 1 : le photographe et le théâtre des ruines

"Ruins of Paris", gravure publiée dans The Illustrated London News, 24 juin 1871

Cette image, paradoxalement, met en avant le travail des photographes tout en représentant le mouvement, ce que la photographie ne peut pas faire. L'interprétation n'en est pas aisée. La composition semble faire écho au discours d'auto-valorisation des photographes. Ainsi Ernest Lacan écrit dans Le Moniteur de la photographie en août 1871 : "parmi les industries qui reprenaient vie au milieu des cendres, la photographie a été la première peut-être à se signaler [...]. À peine s'occupait-on d'embrigader l'armée des travailleurs qui allaient avoir à déblayer les édifices incendiés dont les pompiers disputaient encore les débris [au feu] que déjà le photographe avait commencé son œuvre». Mais, immobile et masqué par son appareil, il semble également inutile au milieu d'une composition marquée par l'urgence des pompiers, et indécent face au deuil d'une famille. Théophile Gautier ne décrit-il pas les photographes comme «encapuchonnés de noir comme des nécrophores, et la tête courbée sur leur boite» ${ }^{1}$ ? 


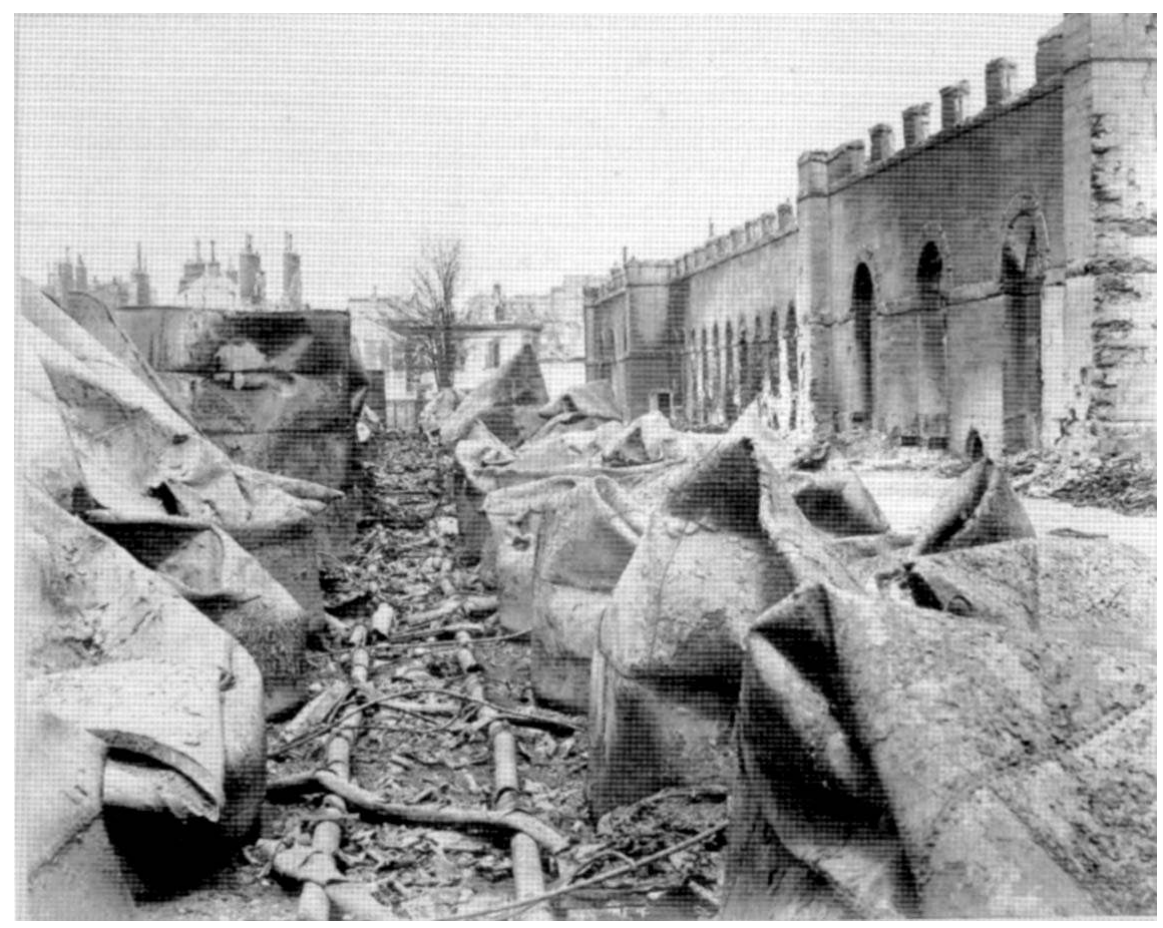

\section{Documents 2 et 3 : Le Grenier d'abondance, boulevard Bourdon : la ruine polymorphe}

Document 2 : Jules Andrieu, «Le réservoir du Grenier d'abondance» dans Désastres de la guerre, 1871, 36 tirages grand folio, Cabinet des estampes du musée Carnavalet.

Jules Andrieu (1816-vers 1874) devient en 1865 le photographe officiel pour le ministère de la Marine et des Colonies. Il réalise en 1869 une série de clichés de ruines au cours d'un voyage en Palestine et en Égypte. En 1871, il se spécialise dans la photographie des destructions parisiennes.

Incendié le 25 mai 1871, le Grenier d'Abondance, boulevard Bourdon, est un cas exemplaire de ruine polymorphe. Relativement négligé par la production écrite, il est beaucoup mieux considéré par l'iconographie. Bâtiment utilitaire, situé à l'extrémité ouest du cœur historique de la capitale, il n'a aucune charge historique ou symbolique, et n'a donc d'intérêt que pour son seul aspect. Vu de loin, on distingue des murs épais, ressemblant vaguement à des murailles et de gigantesques cuves métalliques, tordues par les flammes, qui encombrent le sol. De l'extérieur du bâtiment, l'analogie avec les ruines antiques n'est pas évidente. 


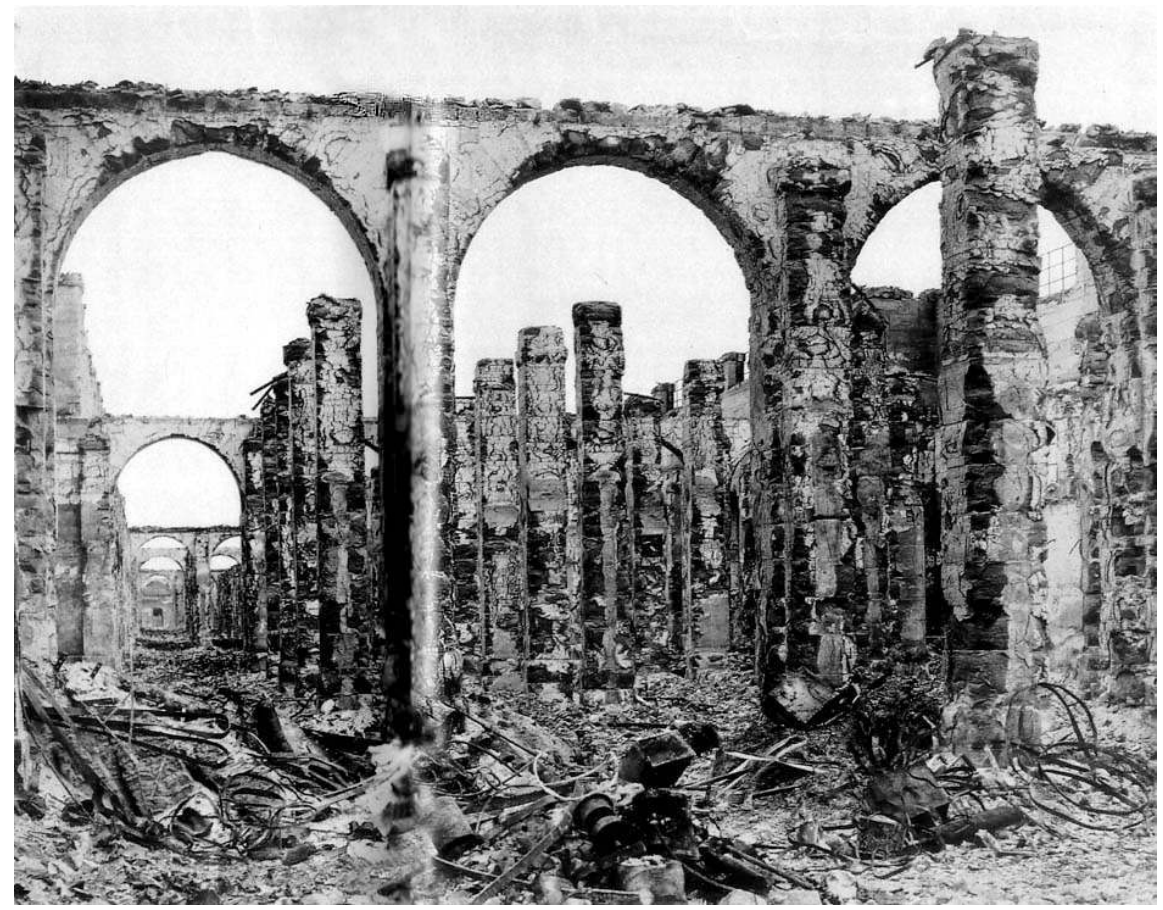

Document 3 : Jules Andrieu, «Ruines du Grenier d'abondance» dans Désastres de la guerre, ouv. cité.

À l'intérieur du bâtiment, un tout autre spectacle apparaît : une longue et pompéienne perspective ouvrant sur l'horizon semble répéter à l'infini un alignement d'arcades et de colonnes. Dans ce décor d'une réelle pureté minérale, la poétique des ruines peut s'exprimer pleinement. Observées de loin, ces ruines ne forment donc qu'un quadrilatère sans grâce ${ }^{2}$; au pied du mur, elles commencent à évoquer quelque peu, grâce à ses murs épais et crénelés, une ruine médiévale, tandis que l'intérieur est un véritable saisissement pour l'amateur de ruines antiques. La même ruine peut donc suggérer, soit l'horreur des dévastations, soit un paysage remarquable.

2. Les Ruines de Paris et de ses environs 1870-1871, album en 2 volumes comprenant 100 tirages in $8^{\circ} \mathrm{obl}$. Texte par Alfred d'Aunay, photographies et éditions par Liébert, Bibliothèque nationale, Cabinet des estampes, Ve 1047 (1-2)-4. 


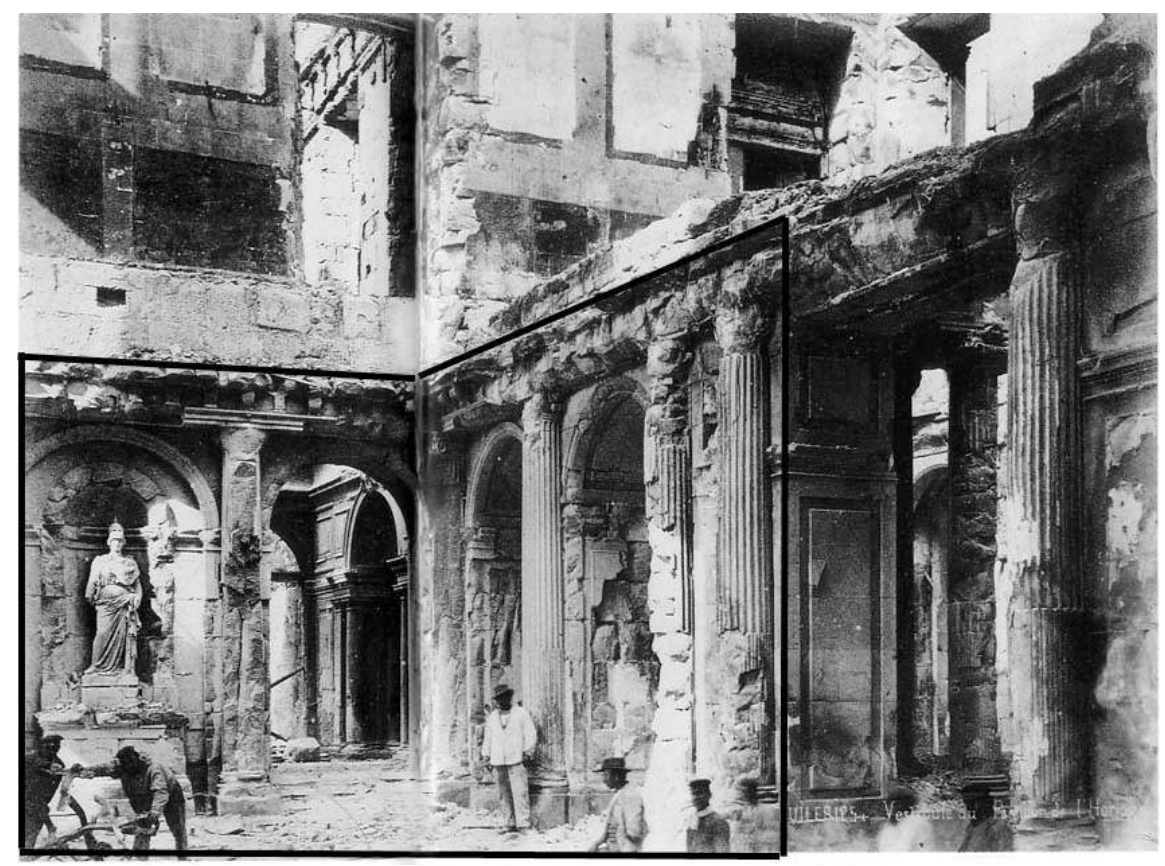

\section{Documents 4 et 5 : l'importance de la composition}

Document 4 (photographie principale) : Louis Lafon, Pavillon d'entrée du palais des Tuileries reproduite dans Bernard NOĖL, La Commune, Paris 1871, Photo Poche Histoire, Paris, Éditions Fernand Nathan, 1998, p. 52.

Document 5 (photographie de l'encadré noir) : Auguste Braquehais, Ruines des Tuileries dans Insurrection de Paris 1871, album de 91 tirages sur carton petit fol. Bibliothèque nationale, Cabinet des estampes, Qe 338.

Auguste Braquehais (1825-1875) était un photographe parisien spécialisé dans les portraits en pied. C'est l'un des rares photographes présents à Paris pendant la Commune et réalisant de véritables reportages photographiques ou des portraits de fédérés.

Au détour d'un couloir, dans le coin d'une pièce, le photographe peut saisir des décors saturés de débris antiquisants. L'accumulation dans un espace restreint de colonnes et de statues préservées dans des niches accréditent les analogies et rendent légitime le déploiement d'une poétique des ruines. Ainsi, Braquehais, visiblement séduit par cette portion de l'intérieur des Tuileries photographie six fois le même endroit sous des angles légèrement différents ${ }^{3}$. Le même lieu, photographié par Louis Lafon, mais sous un angle plus large, montre à quel point les visiteurs doivent être soumis aux codes du pittoresque pour percevoir les ruines. Alors que Braquehais place la statue au centre de ses compositions, et évite d'inclure l'étage supérieur qui ne comporte aucune référence antique, Lafon englobe l'ensemble du décor sans chercher à accentuer l'analogie gréco-latine. Ce dernier privilégie la photographie-témoin intégrant dans le même décor le pittoresque du rez-de-chaussée, la laideur illisible de l'étage et les terrassiers à l'œuvre, tandis que Braquehais fait sien le regard du visiteur en quête de ruines.

3. Insurrection de Paris 1871, album de 91 tirages, ouv. cité. 


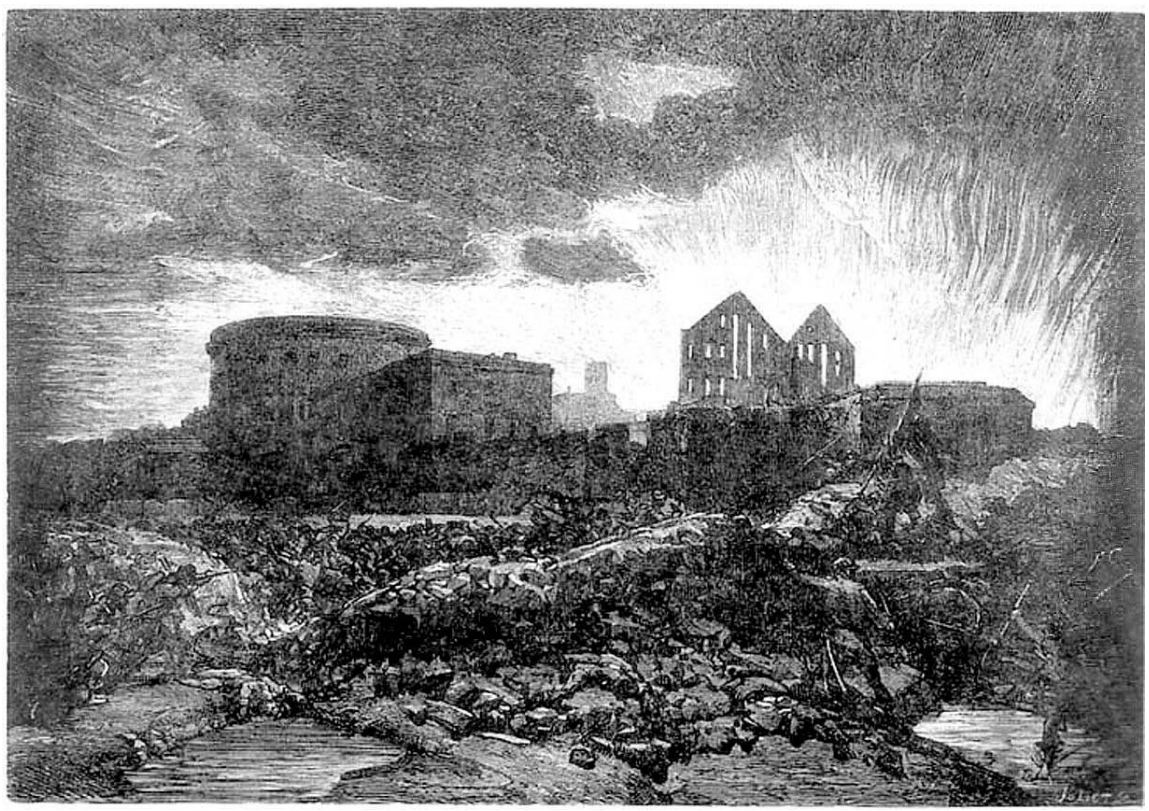

\section{Document 6 : les limites techniques de la photographie.}

François-Nicolas CHIFFART, «Incendies des docks de la Villette», Le Monde Illustré, 17 juin 1871.

François Nicolas Chifflart (1825-1901), issu d'un milieu populaire, étudiant aux Beaux-Arts, prix de Rome de peinture en 1851, renonce peu à peu à une carrière de peintre et se spécialise dans les eaux-fortes. Il illustre notamment des ouvrages de Victor Hugo dont Les travailleurs de la mer. Présent à Paris pendant la Commune, il est brièvement arrêté par erreur.

La destruction des docks de la Villette montre les limites de la photographie. Ensemble de bâtiments utilitaires, sans aucune puissance d'évocation patrimoniale, ils ne forment pas des ruines appréciables aux yeux des amateurs. Les photographies, en des compositions panoramiques, se contentent de fixer l'ampleur des destructions. Comme pour la presque totalité des décombres périphériques, ce sont les ravages de la guerre qui sont montrés (voir document 8 ) En revanche, l'incendie des docks, le 26 mai 1871, a terrifié l'ensemble des témoins. Son intensité est telle qu'ils ont l'impression qu'un cercle de feu barre l'horizon ${ }^{4}$. Au crépuscule, l'incendie devient si imposant qu'il crée même l'illusion d'une confusion du jour et de la nuit. Victor Hugo s'en fait l'écho : «est-il jour? Est-il nuit? Horreur crépusculaire!» 5 . Impuissante à représenter le tourbillon des flammes, peinant encore avec les vues de nuit, la photographie doit laisser ce genre de sujet aux graveurs ou aux peintres.

4. SARREPONT [Eugène Hennebert], Guerre des communeux de Paris 18 mars-28 mai 1871, Paris, Éditions Firmin-Didot, 1871, p. 267.

5. Victor HUGO, L'année terrible, Paris, Éditions Gallimard, 1985, p. 157. 


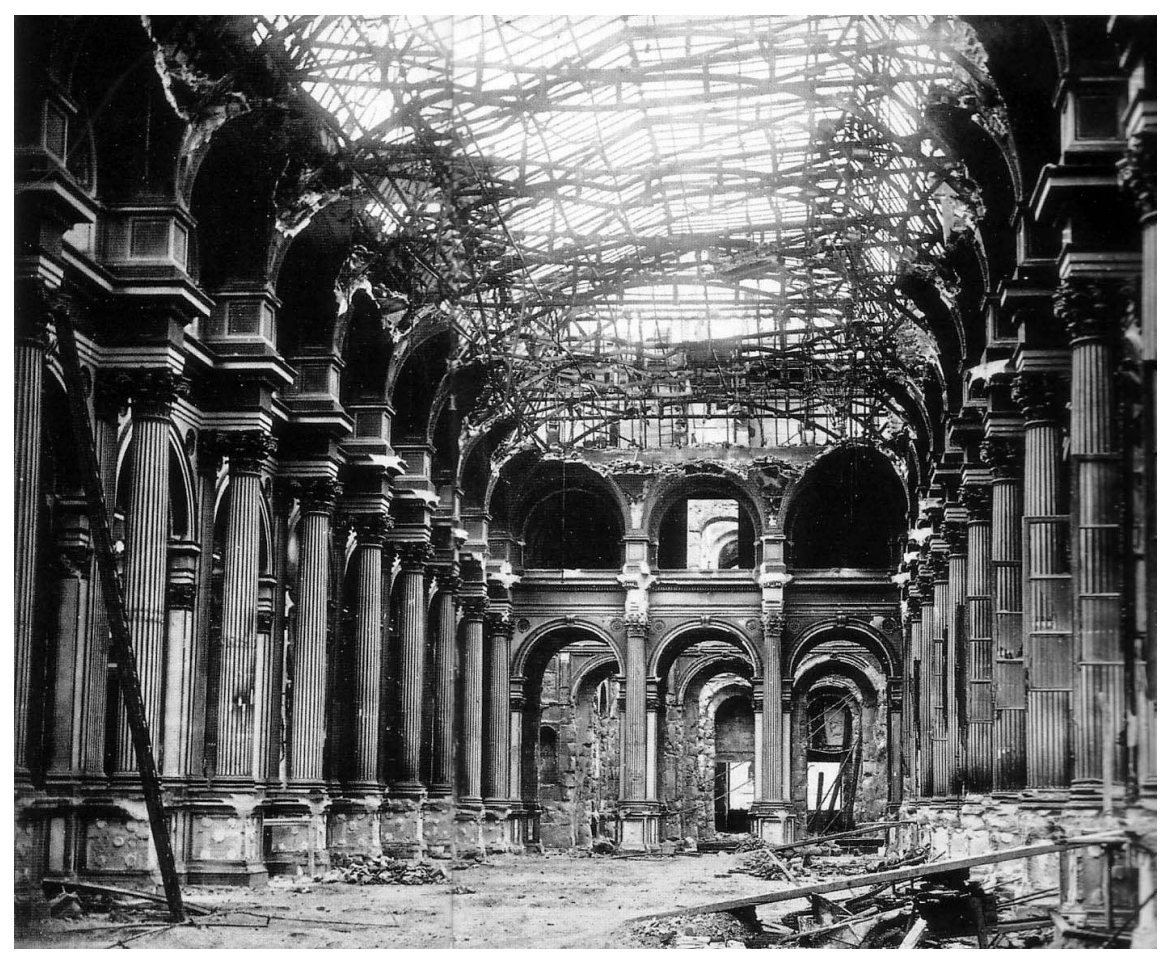

\section{Document 7 : la ruine évidente}

Jules ANDRIEU, Galerie des fêtes de l'Hôtel de Ville, dans Désastres de la guerre, ouv. cité.

Certaines destructions forment des ruines aisément appréciables où le travail du photographe semble réduit au minimum. Ainsi les rigoureux et impressionnants alignements de colonnes et d'arcs-boutants de la galerie des fêtes de l'Hôtel de Ville forment-ils une ruine pittoresque. Pourtant, cette photographie montre la maîtrise de la poétique des ruines par Jules Andrieu. En effet, le cliché est pris au moment précis où le soleil s'immisce à travers les béances du mur. Cette volonté d'ouvrir les perspectives formées par les colonnes et les arcs sur les horizons plus vastes encore du ciel est caractéristique de la poétique des ruines, qui prône l'alliance de la ruine avec les incommensurables espaces naturels. La corporation photographique maîtrise ce type de composition depuis les clichés pionniers d'un Du Camp ou d'un Teynard dans les lumineux paysages orientaux. 


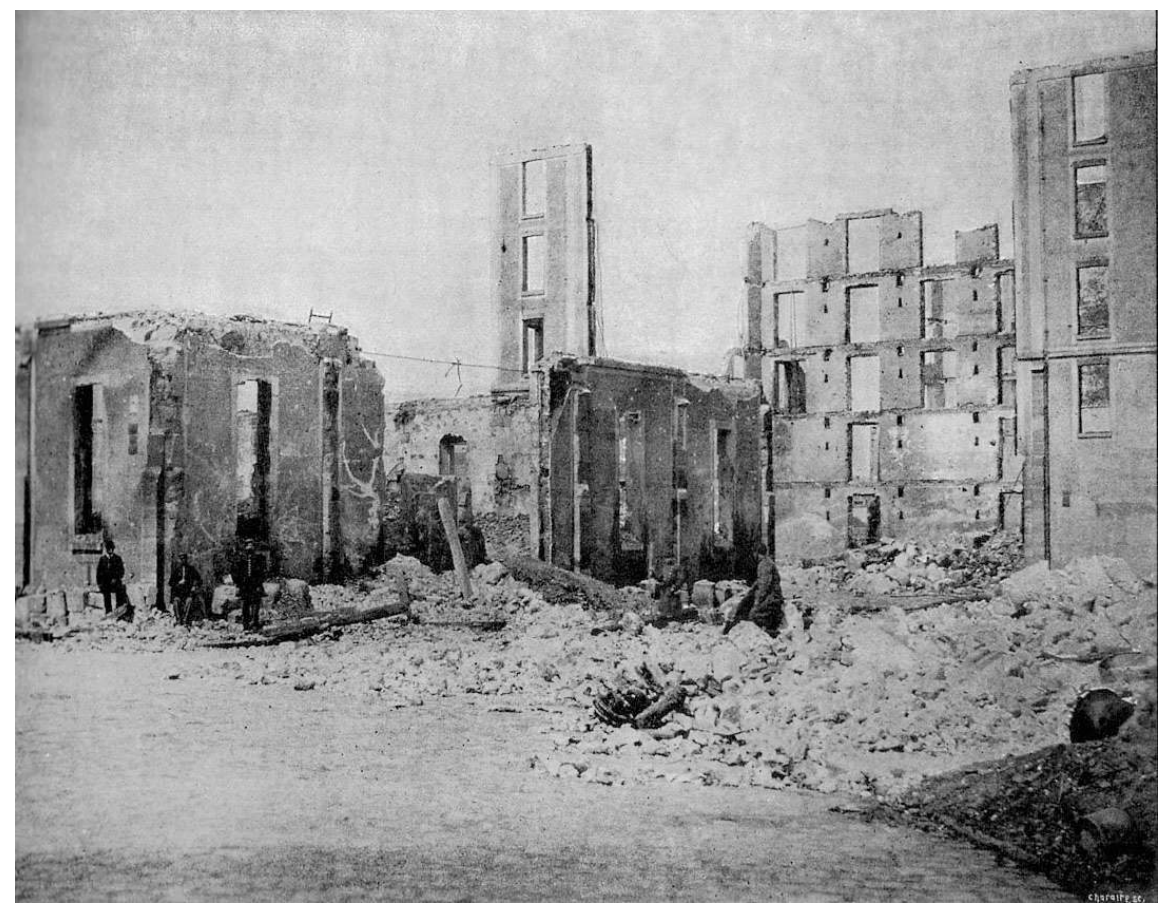

\section{Document 8 et 9 : Décombres périphériques}

Document 8 : Docks de la Villette, dans Paris sous la Commune, par un témoin fidèle la photographie, Paris, Éditions Charaire, 1872.

Ce cliché est représentatif de la plupart des vues des arrondissements périphériques et de la proche banlieue. Il n'y a aucune recherche esthétique, aucune traque de la ruine potentielle mais seulement des débris. Le photographe ne s'aventure pas à l'intérieur des décombres à la recherche du micro-paysage qui pourrait, convenablement cadré, former une ruine honorable. Ici, il s'agit de constituer des archives de la guerre. Trois personnages, en marge de la photographie, difficilement identifiables, montrent les limites de la photographie à représenter le mouvement. 


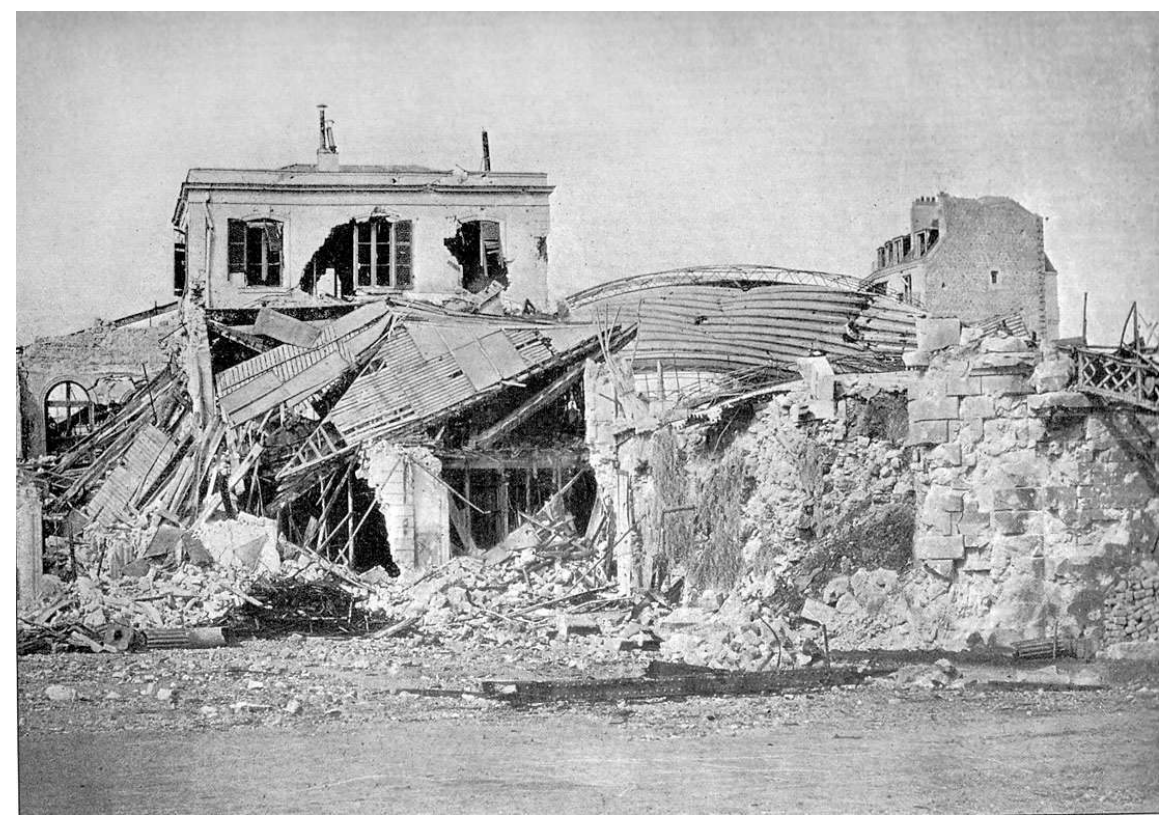

Document 9: Ruines de la gare d'Auteuil dans Paris sous la Commune, par un témoin fidèle la photographie, ouv. cité.

Dans le même ordre d'idées, cette vue des restes de ce bâtiment récent et périphérique, utilitaire, ne recherche pas la ruine mais veut révéler un Paris champ de bataille. L'importance des débris métalliques est intéressante. Absolument incongrus au regard d'une poétique des ruines qui n’a jamais intégré le fer - matériau jugé longtemps indigne d'une architecture monumentale - dans ses codes d'appréciations, ces éléments métalliques ancrent définitivement ces débris dans la contemporanéité. La poétique des ruines est alors inopérante. Ici, les spécificités architecturales, la localisation des décombres et les canons esthétiques contraignent le regard du photographe. 